Issao Minami

Prof. Dr.

Programação Visual / Comunicação Visual

FAUUSP

\title{
Vila de Paranapiacaba, Alto da Serra: um patrimônio ambiental, tecnológico e arquitetônico.
}

Resumo

A importância da ferrovia de São Paulo a Santos: como surgiu e os condicionantes do surgimento da "The São Paulo Railway Co. Ltd."; Vila de Paranapiacaba, Alto da Serra: os aspectos formais e referenciais, seu desenvolvimento de 1860 a 1946; Vila Martin Smith, no Alto da Serra, uma "Model Company Town"

\section{Abstract}

The railways importance in São Paulo: the reasons and conditions for the appearence of the São Paulo Railway C. Ltd; Vila de

Paranapiacaba, Alto da Serra: the formal and referential aspects, your development period from 1860 to 1946; 
Nos Estados Unidos, na região da Nova Inglaterra, no século XIX, a economia da industrialização propiciou o surgimento de diversas "factory towns". Algumas dessas eram aglomerados urbanos projetados e planejados e conhecidas por "Model Company Town" ${ }^{1}$ e eram gerenciadas por organizações do tipo "single-enterprise" 2. Assim, o surgimento da "Model Company Town" norte-americana esteve atrelado à existência de empresas industriais, que através de investimentos em planejamento e construção civil, aliavam desenvolvimento econômico à melhoria da qualidade de vida de trabalhadores alocados nesses empreendimentos.

Por esta época, ou seja, no período que se inicia em meados do século passado ao início deste, sob a égide da Revolução Industrial, o aperfeiçoamento internacional dos meios de transportes permitiu ao Brasil assegurar a sua economia em um "quase" único produto de exportação, o café. Este gradativamente ganha espaço como um bem de grande valor comercial no mercado europeu.

Portanto, enquanto que o fato gerador nos Estados Unidos correpondia às indústrias da țecelagem, da mineração, etc., aqui, no Brasil, a economia estava assentada na agricultura, no desenvolvimento da monocultura cafeeira. 0 café possibilitou a implantação da "singleenterprise" ferroviária no Brasil. A ferrovia trouxe da Europa toda uma tecnologia recéminaugurada pela invenção do vapor, porém aqui em São Paulo enfrentou um grande desafio: vencer os oitocentos metros de desnível que separavam o planalto paulistano da baixada

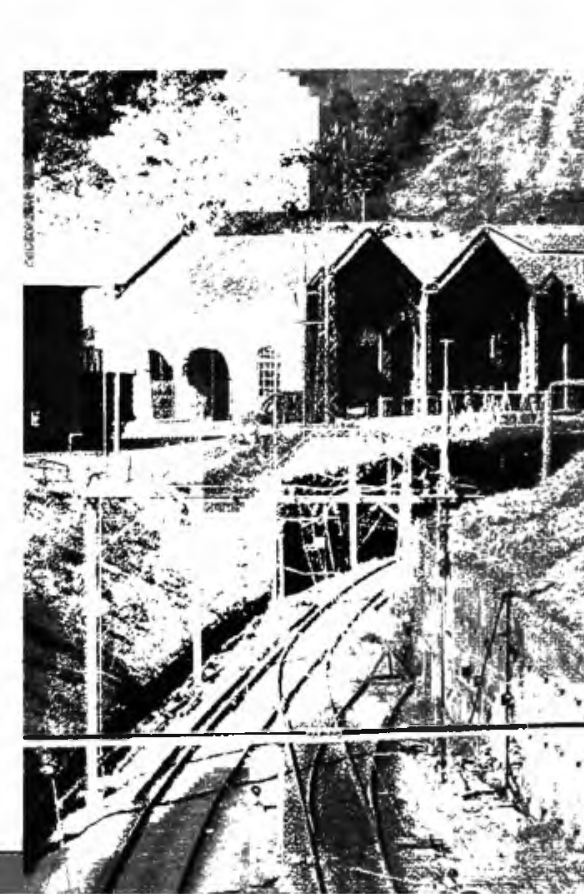
do café do seu terminal exportador, o porto de Santos. A solução deste grande problema exigiu muito tempo e demandou grandes capitais.

Assim, durante os trabalhos de implantação da linha férrea no topo da Serra do Mar, foi necessário erguer acampamentos provisórios ao longo das obras para os trabalhadores Estes foram contratados para desbastar matas, escavar e movimentar terras, bem como para construir o sistema funicular com os planos inclinados e patamares onde foram instaladas as máquinas fixas que acionavam os cabos de aço que movimentavam as locomotivas, na subida e descida da serra. O local escolhido para o acampamento principal, pela companhia empreendedora, ficava no topo da serra e era próximo das obras. Ao seu término, em 1867, a grande maioria do pessoal foi liberada, permanecendo apenas os trabalhadores exigidos para a conservação da via, do maquinário e das operações de tráfegos. Este local, onde a Companhia, circunstancialmente, instalou o pessoal operacional, técnico e administrativo do sistema ferroviário, denominou-se Alto da Serra. ${ }^{3}$

\footnotetext{
1 “Model Company Town" - aglomeraçāo urbana modelar vinculada a uma empresa industrial surgida nos Estados Unidos, na região da Nova Inglaterra entre 1820 a 1870

2 "Single-enteprise" - emprendimento que se caracteriza pela exploraçāo de uma única atividade que no caso da região da Nova Inglaterra era a atividade industrial.
} 
muito bem da aparência das edificações e do seu entorno, implantando serviços de reparos e melhoramentos periódicos, mantendo ruas e jardins bem cuidados, além das fachadas das edificações que recebiam freqüentes pinturas.

Por outro lado, se a "The São Paulo Railway Co. Ltd. " se caracterizou pelo programa de manutenção, ela ofereceu, em primeiro lugar, boas habitações. A parte projetada do Alto da Serra - Vila Martin Smith - independente de ser unidades individuais ou geminadas (duasa-duas ou multifamiliares) ou alojamentos para solteiros, todos possuíam excelentes sistemas de coleta de águas pluviais e de esgoto, ruas e calçadas pavimentadas, abastecimento e rede de água, além de equipamentos sociais e comunitários como escola, play-ground, armazém, clube, etc.

Na Vila Martin Smith, as edificações eram pré-fabricadas, utilizando-se, em sua maioria, madeira de lei. A adoção do sistema construtivo baseado na madeira para as casas possui influência européia, mais precisamente inglesa, pois na ocasião da implantação da Vila Martin Smịth, não se havia, em São Paulo, tradição em construir casas em madeira, quer pela dificuldade em encontrar madeiras de boa qualidade, quer pela inexistência de artesões com domínio no tratamento e uso desse material nas edificações. Suas construções, com telhados de duas águas, possuíam empenas para as ruas, compondo uma espécie de frontão, com seus lambrequins de madeira arrematando os beirais. Esse tipo de telhado que caracterizava a cottage

nova forma de implantação no lote, com recuos e obrigando um distanciamento em relação às edificações vizinhas. Realmente nestas edificações - onde se alojaram os responsáveis pelo pleno funcionamento de todo o sistema funicular, desde os operários mais humildes, passando pelos solteiros até os ferroviários graduados e também engenheiros e técnicos ingleses - foi usada, preponderantemente, a madeira na estrutura e embasamentos, nos ornamentos e detalhes em geral e, em menor proporção, alvenaria de tijolos e elementos metálicos.

Deste modo, a Vila Martin Smith representou uma experiência pioneira em construções de madeira "single style" no Estado de São Paulo, no final do século passado.

Na verdade, o uso da madeira, as características formais e o programa de uso residencial já se faziam evidentes na Vila Velha, no núcleo original do Alto da Serra, onde se concentraram as primeiras edificações avarandadas. A maior parte das casas, localizada nas declividades das encostas do morro (Caminho do Pico da Bela Vista, Caminho do Hospital Velho), em grandes 


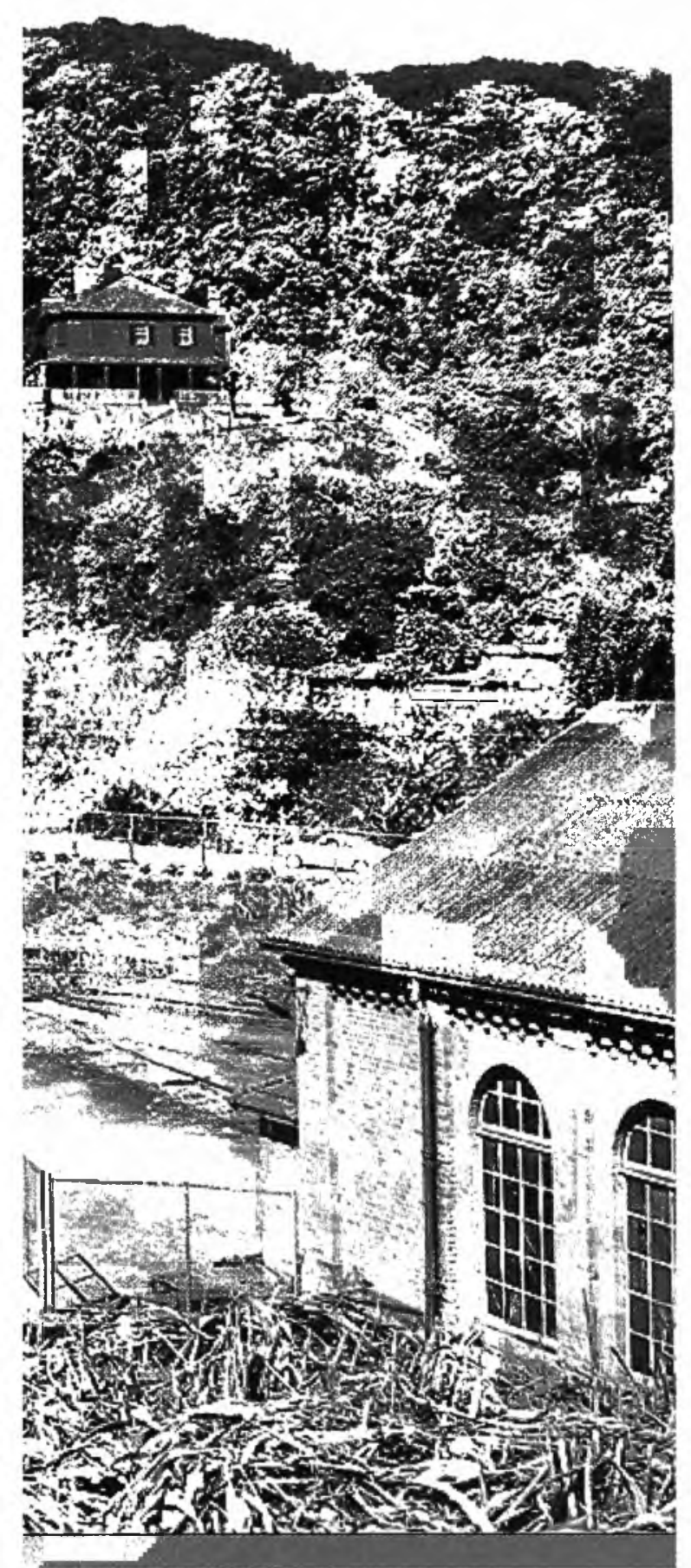

lotes e seguindo as curvas de níveis, se assemelhava a chácaras. A edificação era implantada, geralmente no meio do lote. Sua fachada principal às vezes simétrica, outra vezes não, apresentava em alguns casos uma solução mista de madeira com alvenaria de pedras. Nessa fachada aparecia a chaminé da lareira ou fogão a lenha e era comum a inscrição com os dizeres: "SPR" em ferro fundido, colocado no vão de um óculo central.

Outro aspecto a destacar no Alto da Serra são as características de modernidade que se pode observar através do sistema de infraestrutura e dos aspectos culturais europeus nele presentes. Alto da Serra muito embora afastada dos núcleos urbanos maiores no início do século, possuía uma moderna infra-estrutura para a época e realidade brasileira: abastecimento de água e de esgoto, canalização de águas pluviais, sistema de calefação, além de sofisticado sistema de identificação de logradouros.

Portanto, a "The São Paulo Railway Co. Ltd." planejou e empreendeu a construção e administração de uma vila operária que nasceu e sempre viveu em função de uma única atividade, onde imperou uma relação de paternalismo entre trabalhadores e a empresa. A Vila Martin foi um modelo de núcleo urbano ferroviário implantado em solo brasileiro, cujas características se reproduziam nas cidades operadas por "single-

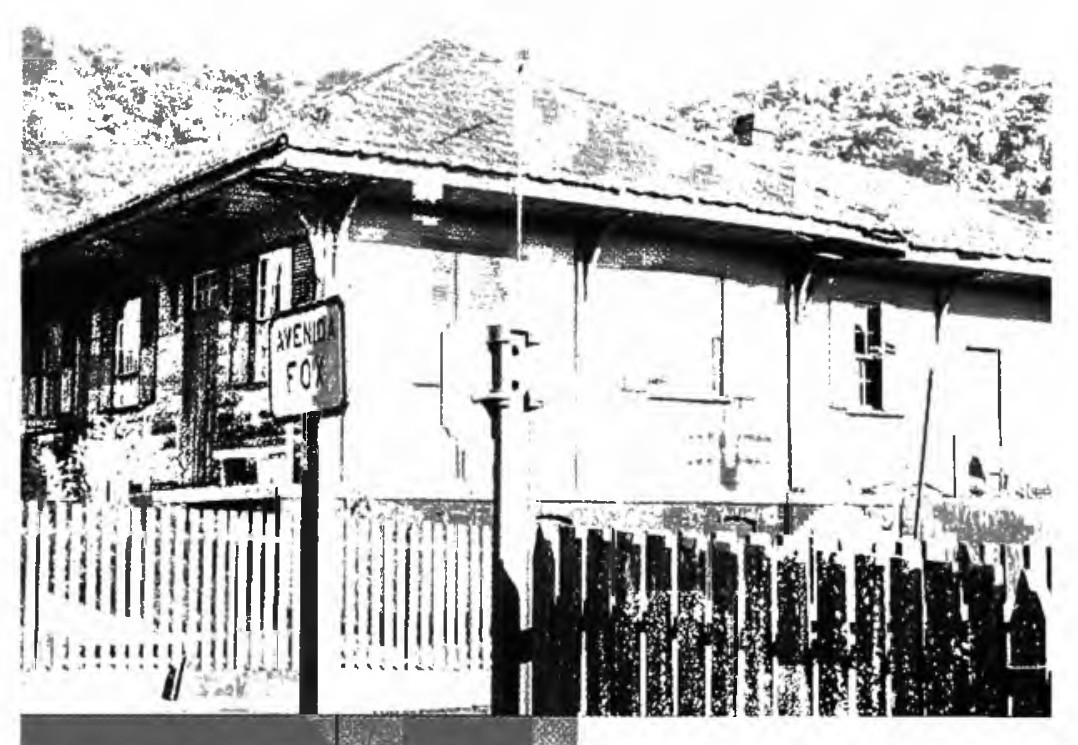
enterprise" com atividades industriais da região de Nova Inglaterra, nos Estados Unidos - South Manchester, Peace Dale, Ludlow, Fairbanks Village e Hospedale onde imperavam um saudável aspecto visual e onde a interação entre a sociedade e a paisagem era produtiva e saudável. Razões pelas quais foram consideradas "Model Company Town"

Podemos dizer também que este sui generis aglomerado urbano em solo brasileiro comportava soluções construtivas com traços comuns às existentes na "Model Company Town" norte-americana, tanto pela origem, administração e período, quanto pelo sistema construtivo e materiais. Assim, ambos, a Vila Martin Smith e a "Model Company Town" eram produtos oriundos de um mesmo agente gestor: a "single-enterprise"

Assim, a "The São Paulo Railway Co. Ltd." constituiu um dos empreendimentos com a participação inglesa, pioneiro, no Brasil, na construção e exploração ferroviária. Vila operária, que nasceu e sempre viveu em função de uma única atividade, onde imperou uma relação de 
paternalismo entre trabalhadores e a empresa. Vila de Paranapiacaba, outrora Alto da Serra, foi um modelo de núcleo urbano ferroviário implantado em solo paulista no final do século passado.

Por todas estas razões é que a Vila Martin Smith, constitui um exemplo de "Model Company Town"

Após a encampação, 1946, pelo governo federal, aos poucos, o parque ferroviário foi sendo desativado e na atualidade, o conjunto - ferrovia mais vila e o seu entorno - apesar de tombado pelo Condephaat como um bem cultural, padece. Em respeito, a pelo menos seu memorável passado, necessita-se com urgência de medidas que impeçam a deterioração de seu espaço. Não se pode mais adiar as medidas que se fazem necessárias, urgentemente, para a sua destinação social maximizando o significado do patrimônio cultural: "arquitetura ferrovia - meio ambiente". As propostas de revitalização têm que levar em conta o trinômio acima, abrindo caminho a um potencial turístico, vocação natural da localidade. Potencial este que deve ser a exploração não predatória pelos turistas e o engajamento e o incentivo à participação comunitária através de movimentos nascidos no seio desta comunidade; ser o envolvimento decisivo dos órgãos competentes para a solução concreta das questões de sua responsabilidade e busca dos recursos públicos e privados para a implementação de propostas. É necessário acordar. Ainda é tempo. 0 momento exige seriedade

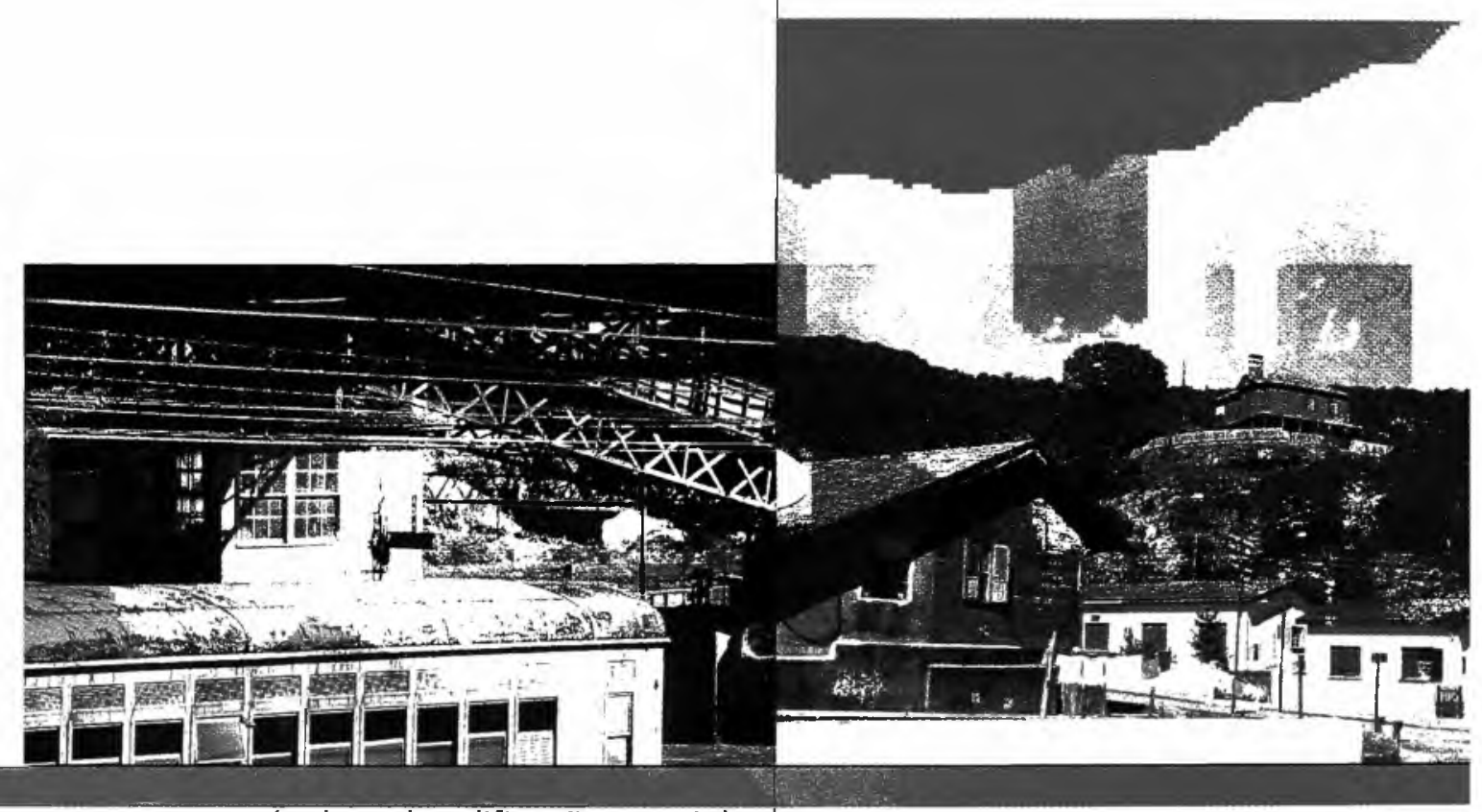

condições deste patrimônio em destruição. Com certeza, por trás de cada edificação em pinhode-riga e de cada plano inclinado da ferrovia batalha-se incessantemente, pela preservação deste patrimônio e pela liberdade de se criar e discutir conjuntamente os caminhos necessários, razão de ser do próprio homem resgatando seu passado autofágico, buscando seu espaço presente e suas necessidades vitais futuras para o enriquecimento da relações sociais e humanas. 


\section{Bibliografia}

CUNHA, José A.D. et al, Minami, Issao (orient.). Paranapiacaba: tipologias habitacionais. São Paulo: FAUUSP, 1990 (mimeo).

DOWNING, Andrew J. The architecture of country houses. New York: Wilwy and Putnam, 1850.

FÉLIX, Antonio C. et al, Minami, Issao. Paranapiacaba: sistema de sinalização. São Paulo: FAUUSP, 1992 (mimeo).

FERREIRA, J. et al. Paranapiacaba: estudos e memória. Santo André: Public, 1990.

GARNER, John S. The model company town; urban design through private enterprise in ninetheenth-century New England. Amherst: University of Massachussetts, 1984.

KUNIYOSHI, Celina. A Vila de Paranapiacaba e a Estrada de Ferro Santos-Jundiaí. In: São Paulo (Estado). Secretaria de Estado da Cultura. Condephaat. Processo $n^{\circ} 22.209 / 82$ : Inventário sistemático dos bens culturais do Estado de São Paulo. São Paulo: 1986 (mimeo).

LEMOS, Márcia Tancler de. 0 impacto da ferrovia no nosso meio e as construções da cidade de Paranapiacaba. In: São Paulo (Estado). Secretaria de Estado da Cultura. Condephaat. Processo $n^{\circ}$ 22.209/82: Inventário sistemático dos bens culturais do Estado de São Paulo. São Paulo: 1986 (mimeo).

MCALESTER, Virginia $S$ and Lee. A field guide to american houses. New York: Alfred A. Knopf, 1984.

MINAMI Issao. Vila Martin Smith, no Alto da Serra, em São Paulo, um exemplo típico de "Model Company Town". São Paulo: FAUUSP, Tese (doutorado), 1985.

. Expressão e representação do espaço urbano por meio da codificação visual da imagem: memória da Vila de Paranapiacaba. São Paulo FAUUSP. Dissertação (mestrado), 1983.

Retrato de corpo e alma: imagem e o imaginário do $A B C$ (I). In: Congresso de história da região do ABC, Santo André, 1990. Anais. Santo André: Bartira, 1990. p.93-100.

-WAKARA, Julio Abe. Histórico de Paranapiacaba. Santo André: Comissão Pró-Paranapiacaba, 1983.

et al. Paranapiacaba 1972. São Paulo: FAUUSP, 1972 (mimeo).

MÔNACO, Cristina H. et al., MINAMI,Issao (orient.). Paranapiacaba, levantamento histórico. São Paulo: FAUUSP, 1982 (mimeo).

Negrelli, João G. Minha terra e minha gente; reminiscência. Santos: se, 1981 (mimeo).

SCULLY Jr. Vincente J. The shingle style and stick style. Architectural theory and design from Downing to the origins of Wright. New Haven: Yale University Press, 1974.

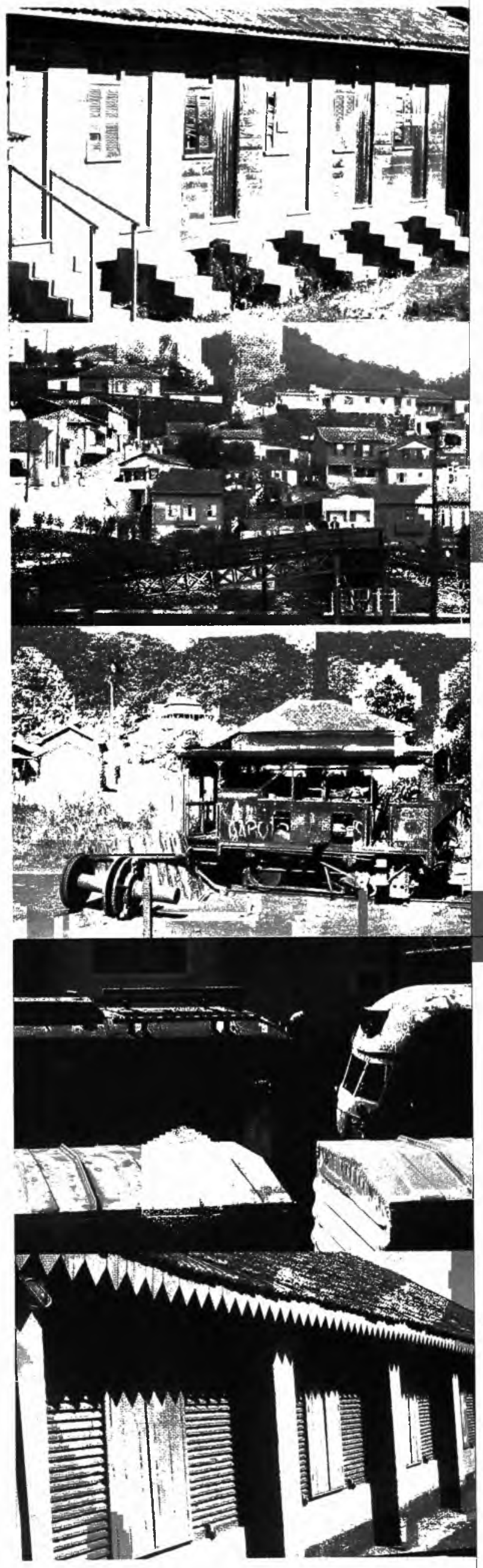

Artigo baseado na tese de doutoramento: Vila Martin Smith, no Alto da Serra, em São Paulo, um exemplo típico de "Model Company Town", defendida pelo autor no Curso de Pósgraduação da Faculdade de Arquitetura e Urbanismo da Universidade de São Paulo em 10/03/1995. 